\title{
Intelligent Sensing Using Metal Oxide Semiconductor Based-on Support Vector Machine for Odor Classification
}

\author{
Nyayu Latifah Husni ${ }^{1}$, Siti Nurmaini' ${ }^{2}$ Irsyadi Yani ${ }^{3}$, Ade Silvia ${ }^{4}$ \\ ${ }^{1,4}$ Electrical Department, Politeknik Negeri Sriwijaya, Indonesia \\ ${ }^{2}$ Intelligent System Research Group, Faculty of Computer Science, Universitas Sriwijaya, Indonesia \\ ${ }^{3}$ Mechanical Engineering Department, Faculty of Engineering, Universitas Sriwijaya, Indonesia
}

\section{Article Info}

Article history:

Received Nov 21, 2017

Revised Jun 10, 2018

Accepted Aug 4, 2018

\section{Keyword:}

Intelligent sensing

MOS sensor

Odor classification

Support vector machine

\begin{abstract}
Classifying odor in real experiment presents some challenges, especially the uncertainty of the odor concentration and dispersion that can lead to a difficulty in obtaining an accurate datasets. In this study, to enhance the accuracy, datasets arrangement based on MOS sensors parameters using SVM approach for odor classification is proposed. The sensors are tested to determine the sensors' time response, sensors' peak duration, sensors' sensitivity, and sensors' stability when applied to the various sources at different range. Three sources were used in experimental test, namely: ethanol, methanol, and acetone. The gas sensors characteristics are analyzed in open sampling method to see the sensors' performance in real situation. These performances are considered as the base of choosing the position in collecting the datasets. The sensors in dynamic experiment have average of precision of $93.8-97.0 \%$, the accuracy $93.3-96.7 \%$, and the recall 93.3-96.7\%. This values indicates that the collected datasets can support the SVM in improving the intelligent sensing when conducting odor classification work.
\end{abstract}

Copyright (c) 2018 Institute of Advanced Engineering and Science. All rights reserved.

\section{Corresponding Author:}

Siti Nurmaini,

Intelligent System Research Group, Faculty of Computer Science,

Universitas Sriwijaya, Jalan Raya Prabumulih Inderalaya,

Palembang, South Sumatera, Indonesia.

Email: siti_nurmaini@unsri.ac.id

\section{INTRODUCTION}

Sensors as one of the important devices in electronic systems have received people's attention. Enormous capability of sensors as inputs of information processing has been developed within the electronics industry [1]-[4]. Light sensors and gas sensors are two of existing sensors that have been most actively studied. Gas sensors are defined as a device that can substitute human olfaction. Air quality monitoring [5]-[7], gas leakage localization [8],[9], forest monitoring [10],[11], military [12],[13], are some examples of gas sensor applications. Gas sensors convert the environment physical phenomenon (in this case pollutant concentration) into electrical signals. They represent part of the interface between the physical world and the world of electrical devices, such as computers [6]. They can be integrated in two modes, mobile and static, however, the later has limitation in covering a large area. Static sensors can be brought by worker to detect the surrounding; unfortunately, applying them to dangerous and poisonous area can harm the worker. Mobile robots utilization can cope the problems. They give more advantages concerning safety and security [14], such as: i) being able to be deployed to the dangerous area without being afraid of to be killed; ii) also being able to be used to monitor the environmental air quality continuously without being tired or giving inaccurate information; and iii) offering cheaper cost in training them [15].

Metal Oxide Semiconductor (MOS) sensors are one of the most investigated groups of gas sensors. There were a lot of researches used them as their sensors [16]-[20]. The reasons of choosing this sensor are 
due to: i) low cost and flexibility associated to their production; ii) simplicity of their use; iii) large number of detectable gases/possible application [21]; and iv) robust, light weight, fast response [22]. Although this type of sensors showed their advantages, however, the deployment of gas sensors in real environment faces some other problems, such as the phenomenon of patches and eddies that occur due to the turbulent airflow of the wind [23],[24]. The concentration decreases when molecules move away from the source, hence molecular diffusion and turbulent diffusion processes have the main role in determining the shape of plume. Molecular diffusion causes random motion of the molecules to move gradually apart, while turbulent diffusion tears apart the cloud of molecules physically by air turbulence [25]. Molecular diffusion effect on the plume shape can be neglected [24] due to its small effect on the plume shape. It is contradictive with turbulent diffusion that can change the shape of the plume. The turbulent diffusion that dominates the dispersion of odor molecules becomes crucial parameter in odor research. Some researchers have investigated the odor characteristics in airflow environment [26]-[28] and in turbulence environment [29],[30]. Most of the gas sensors' works were done in simulation [31]-[33]. Some researchers who had a great desire to work in real experiment usually set some limitations on their environment (in conditioned experiment and scalable environment) [24],[34] and gave more consideration on an intelligent sensing as their improvement.

Intelligent sensing in odor classification refers to an intelligent approach that supplied to the sensors to increase their abilities in detecting and classifying substances. In ancient research, the conventional technique was applied to the sensors to enhance sensors capabilities. The characteristics of this research were based on the sensor superiorities platform. The sensors were equipped with various powers, i.e. a very special sensor with a proper ability that was produced only to detect a particular substance. This approach gave a simplicity concerning data processing and computation due to the sensors had a good selectivity; however the sensors improvements needed more time and money [35]. Artificial Intelligent (AI) offered a good solution to overcome the problems. It can build ideal performance [36] and gave a high accuracy [37]. Neural Network (NN) [38]-[41], k-nearest [31], Principal component analysis (PCA), clustering analyses (CA) [31], and Support Vector Machie (SVM) [42]-[45] are some algorithms that usually be used as the odor classifiers. Sarkar have proposed SNN (Spiking Neural Network) to classify black tea odor [38],[39]. The proposed method was successful to classify the tea odor data; however, its learning algorithm needed a bigger architecture so that it made the computation become slower, easily to be trapped in local minima, could not run well if the data was incomplete, and had bad predicition [46]. Yu [47] had compared three algorithms (k$\mathrm{NN}, \mathrm{BPN}$, and SVM) and found that SVM produced more accurate classification. SVM had some superiorities [48], such as: i) SVM is formulated as a quadratic programming problem with no local minima, ii) The architecture of the model (number of support vectors) is automatically selected during the optimization process, iii) SVM can be applied for multi-class problems, iv) They can generalize well from a restricted amount of training data. This is particularly interesting in the gas sensor area where it is very costly and time-consuming to obtain a large reliable and representative set of examples.

SVM approach for odor classification have been applied in many works [44],[49],[50]. Marco [44] investigated the classification in continuous monitoring for obtaining an accurate datasets. It was really difficult to get the steady state of the sensors due to the sensors were not continuously exposed to the odor sources for enough time. Another research conducted by Amy Loutfi [49] who used the transient response of the sensors. In that research, the sensors were assumed to be in a state of transition and the input to the classification algorithm was taken from the comparison between a baseline and steady state; however, it still was not easy to get good datasets. Osuna [50] stated that in the compression of the data, the sensor transient response did not improve the accuracy prediction but impair the accuracy. It could be concluded that the database was over fitting [50] and the conclusion about the best databases for the odor classification was still vague.

In this research SVM approach based on the MOS performance was proposed to overcome the problem of collecting the databases for a training datasets. The characteristic of the MOS sensors' response time, sensors' peak response duration, the sensitivity and the stability response of the sensor were investigated. The main goal of this research is to analyze the active coverage area of gas sensors. By having the sensor's performance data, a planning of finding an appropriate location for taking datasets of SVM could be set up. To the author's knowledge, there is no one discussed about the performance of gas sensors for the odor classification. It is hoped that the MOS sensors' performance can help to find a good datasets for SVM. This paper consists of 5 parts, i.e.: part 1 describes the background of the research, part 2 introduces parameters in odor classification tasks, part 3 describes the experimental setup, part 4 displays the result and the discussion of the experiment, and part 5 is the conclusion of the research.

Int J Elec \& Comp Eng, Vol. 8, No. 6, December 2018 : 4133 - 4147 


\section{PARAMETERS IN ODOR CLASSIFICATION TASKS}

\subsection{Gas Sensors Performances}

The MOS sensors are suitable for recognizing either reducing or oxidizing gases by or conductive measurements [51]. Sensor's performance is one of the important parts of the sensor application. By knowing the performance, it can be easily applied to an appropriate application with certain limitation and scope. According to V. E. Bochenkov [52], Some of parameters should be paid attention in order to characterize sensor performance, namely: sensitivity, selectivity, stability, detection limit, dynamic range, linearity, resolution, response time, recovery time, working temperature, hysteresis, and life-cycle. Sensitivity is a change of measured signal per analyte concentration unit [52]. Xin Zhou in [53] analyzed the sensitivity of the gas sensor based on $\mathrm{ZnFe}_{2} \mathrm{O}_{4}$ spheres and $\mathrm{ZnFe}_{2} \mathrm{O}_{4}$ nanoparticles. The gas sensor's response to the $30 \mathrm{ppm}$ and $100 \mathrm{ppm}$ acetone were recorded. The gas sensor's response to the acetone varied with the change of the temperature. Gas sensor gave low response to the acetone at low temperature $\left(200^{\circ} \mathrm{C}\right)$ due to acetone molecules cannot effectively react with the surface absorbed oxygen species. The responses of porous $\mathrm{ZnFe} 2$ $\mathrm{O} 4$ spheres were good at higher temperature at operating temperature $200^{\circ} \mathrm{C}$ and $237.5^{\circ} \mathrm{C}$.

Selectivity refers to characteristics that determine whether a sensor can respond to a group of analytes selectively or even to a single analyte specifically. Selectivity is one of essential parameters in odor identification [54]. Selectivity will be easy if the odors to be identified are really different. It is contradictive when the odors are quiet similar as in paper [31]. The selectivity of the sensors will be better by additional methods or techniques, such as the integration of PCA, LDA, NN, SVM, etc. Selectivity has a tight relation with the stability that refers to the ability of a sensor to provide reproducible results for a certain period of time. It includes retaining the sensitivity, selectivity, response, and recovery time. One of the gas sensor's stability was conducted by Zhen Wen [55]. They tested several gas sensor's parameters in their research, such as: sensitivity, detection limit, working temperature, response/recovery kinetics, selectivity, and stability of the sensor. In that research, they got that Rhombic $\mathrm{Co}_{3} \mathrm{O}_{4}$ nanorod (NR) array-based gas sensor had a good stability over the 3 months test.

Working temperature is the temperature that corresponds to maximum sensitivity. Porous $\mathrm{ZnFe} 2 \mathrm{O} 4$ spheres were good at operating temperature $200^{\circ} \mathrm{C}$ and $237.5^{\circ} \mathrm{C}$; it means that the working temperature range of that sensor was $200^{\circ} \mathrm{C}$ until $237.5^{\circ} \mathrm{C}$. It is due to the sensitivity of the sensor become quite high in that range. Another example of working temperature can be seen from the research of Zhen Wen [55] that analyzed some parameters in gas sensor's performances. Ethanol analyte was chosen as the gas source in their research. The optimal working temperature of Rhombic $\mathrm{Co}_{3} \mathrm{O}_{4}$ nanorod array based gas sensor for maximum sensitivity was at $160^{\circ} \mathrm{C}$. The response of the sensor increased with the operating temperature and then decreased with a further rise of the operating temperature. The phenomena were explained by Zhen Wen using the adsorption and desorption kinetics on the surface of the semiconducting metal oxides. When the working temperature was small (below $150^{\circ} \mathrm{C}$ ), the chemical activation was also small; therefore the response was also small (below 10). The adsorbed gas molecules escaped before their reaction if the operating temperature was really high (above $200^{\circ} \mathrm{C}$ ). The response would also decrease (below 10). The working temperature was between $150^{\circ} \mathrm{C}$ until $200^{\circ} \mathrm{C}$, with the highest sensitivity at $160^{\circ} \mathrm{C}$.

The other MOS performances were described as follows: Detection limit is the lowest concentration of the analyte that can be detected by the sensor under given conditions, particularly at a given temperature. One of the selective detection researches was offered by Qianqian [56] who observed $\mathrm{ZnO}$ gas sensor to the acetone sources. The research obtained that detection limit for the acetone was $0.25 \mathrm{ppm}$. Dynamic range refers to the analyte concentration range between the detection limit and the highest limiting concentration. Linearity refers to the relative deviation of an experimentally determined calibration graph from an ideal straight line. Resolution means the lowest concentration difference that can be distinguished by sensor. Response time is the time required for sensor to respond to a step concentration change from zero to a certain concentration value. Qianqian [56] analyzed the response time of the $\mathrm{ZnO}$ sensor to the acetone. The response time of the sensor was as short as $3 \mathrm{~s}$. Recovery time is the time it takes for the sensor signal to return to its initial value after a step concentration change from a certain value to zero. Hysteresis means the maximum difference in output when the value is approached with an increasing and a decreasing analyte concentration range. Life cycle is the period of time over which the sensor will continuously operate.

\subsection{Dispersion Model}

The gas can move easily from one place to another place due to the wind or the difference of concentration in one place. The longer the distance of the gas from the source is, the smaller the concentration will be. In other word, the concentration near the source will be higher than the concentration of the gas far from the source. The turbulence and the diffusion that can cause the gas to move are influenced by the environmental condition, especially the wind characteristics. The movement of the gas from its source to the area around it will produce a concentration pattern or always called as the plume dispersion. 
The change of the concentration pattern will continuously happen in accordance with the occurrence of the wind that moves in the same direction or in the different direction.

The plume dispersion can be modeled using mathematic equation. In general, the models can be divided into two forms, i.e., i) Basic Model; and ii) Diffusion Model. In basic model, the gas only moves due to the air flow speed. The concentration using this model is considered to be constant. Thus, the concentration in one place in one time is the same with the concentration in another place in different time. The basic model uses the equation as represented in equation (1):

$$
\frac{\partial \mathrm{C}}{\partial \mathrm{t}}+\mathrm{u} \frac{\partial \mathrm{C}}{\partial \mathrm{x}}=0
$$

where $C$ is gas concentration $\left(\mathrm{kg} / \mathrm{m}^{3}\right), u$ denotes the air flow speed $(\mathrm{m} / \mathrm{s}), t$ shows the time $(\mathrm{s})$, and $x$ is coordinate $(\mathrm{m})$. For the diffusion models, there were a lot of researchers offered some solutions. In paper [57], Gaussian models and Farrel's filamentous model were discussed. These models assumed the meteorological condition and plume emission are stationary. The gas concentration can be stated in two forms, i.e. 2 and 3 dimensions that can be seen in the following equations:

$$
\begin{aligned}
& C(x, y, t)=\frac{M}{L_{z} 4 \pi t \sqrt{D_{x} D_{y}}} \exp \left(-\frac{\left(x-x_{0}-u t\right)^{2}}{4 D_{x} t}-\frac{\left(y-y_{0}-v t\right)^{2}}{4 D_{y} t}\right) \\
& C(x, y, z, t)=\frac{M}{(4 \pi t)^{3 / 2} \sqrt{D_{x} D_{y} D_{z}}} \exp \left(-\frac{\left(x-x_{0}-u t\right)^{2}}{4 D_{x} t}-\frac{\left(y-y_{0}-v t\right)^{2}}{4 D_{y} t}-\frac{\left(z-z_{0}-w t\right)^{2}}{4 D_{z} t}\right)
\end{aligned}
$$

\section{MATERIALS AND METHOD}

\subsection{Experimental Setup}

Three Metal Oxides gas sensors (TGS 2620, TGS 2602, and TGS 2600) were used in this experiment. These sensors are combined together in order to make an array sensor. The sensing element of the gas sensors is made of a metal oxide semiconductor layer formed on the alumina substrate of a sensing chip together with an integrated heater. The response pattern of the sensors' array was analyzed in the real environment in order to see the characteristics and performance of each sensor (The use of more than one sensor in odor classification is very important due to the output of one sensor can refer to different concentration of various analytes) [58].

In this research, the data of the sensor performance will be analyzed in four categories, namely: sensors' time response, sensors' peak duration, sensors' sensitivity, and sensors' stability. The experiment was done in a room of $4 \mathrm{mx} 10 \mathrm{~m}$. The responses of the sensors were measured using 2 scenarios. For checking the sensors' response time and sensors' peak duration, the source was exposure to the environment for $20 \mathrm{~s}$. The distances of the sensors to the sources were varied, i.e. by moving the robots $60 \mathrm{~cm}$ from its initial position. The source was switched into on and off condition to see the sensitivity of the sensors. The simple block diagram of the gas sensor development is shown in Figure 1 (a). The temperature of the sensor will not be discussed in detail due to the data got from the first step in this research would be supplied as the datasets of odor classification which was done in the real environment (the environmental temperature was taken around $28{ }^{\circ} \mathrm{C}$ until $31{ }^{\circ} \mathrm{C}$ ).

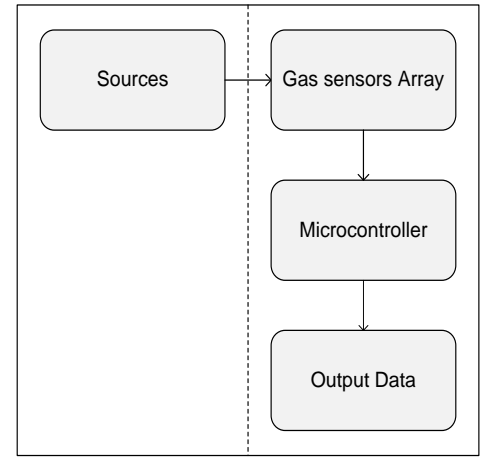

(a)

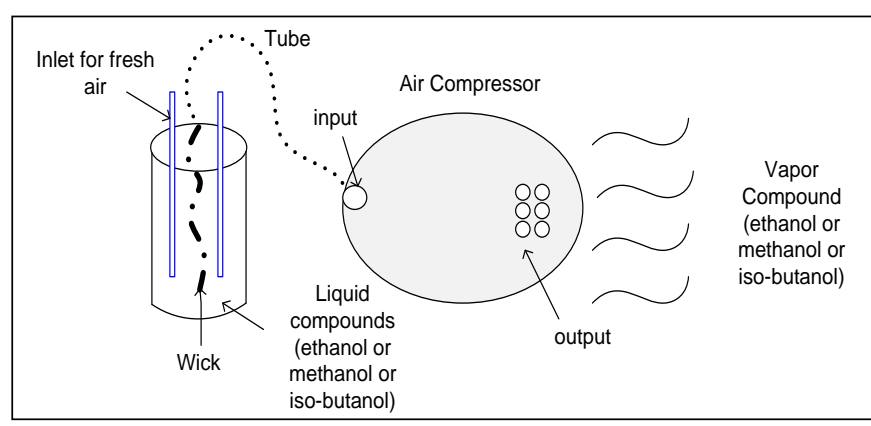

(b)

Figure 1. (a) The block diagram of gas sensors development, (b) The gas sources setup 
Figure 1(a) shows the block diagram of gas sensors development. The chemical sources detected by sensors array were being converted into physical parameter. It was then processed in microcontroller to obtain the sensor response. In this research, the output was also sent to the computer by means of wireless communication. The ADC data of the sensors were observed and processed to get the value of sensor's response.

To validate gas sensors' performance, the experiments were tested in open environment. In most works, the data was obtained using a chamber [58]-[60] where the sensors were placed in and injected sources through a tiny tube. In this research, the experimental source was set as shown in Figure 1(b). The source set-up imitated the odor sources introduced by Thomas Lochmatter [15]. The sources used in this experiments were ethanol $\left(\mathrm{C}_{2} \mathrm{H}_{6} \mathrm{O}\right)$, methanol $\left(\mathrm{CH}_{3} \mathrm{OH}\right)$, and acetone $\left(\mathrm{C}_{4} \mathrm{H}_{10} \mathrm{O}\right)$. Liquid sources were transformed to be gas using the help of the wick and the fresh air supplied to the sources' chamber. The wick and a piece of tube (for the fresh air inlet) were used to increase the air-ethanol interface surface. Evaporated ethanol was mixed with the air on the top part of the chamber. The mixed gas was then pumped toward the gas outlet. The air pump used as the experimental sources had capability to exhaust 14.0 Littre liquid source in a minute. It has six outputs that enable the deployments of the sources to any possible and desired points. The pressure of the pump is more than $0.016 \mathrm{MPa}(\approx$ more than $2.32 \mathrm{psi})$ with $50-60 \mathrm{~Hz}$ frequencies. The type of the pump is a diaphragm pump that allows the output (in this case ethanol concentration) to be controlled. In addition, it is equipped with a knob that can be turned around from the lowest pressure to the highest one that offered an easiness of controlling the concentration.

\subsection{SVM Approach}

In this research, Arduino Mega and Raspberry were used as intelligent sensing controllers. The signal sensed by the sensor array was sent to the Arduino Mega. The signal was then converted to digital signal in the Arduino. The digital signal was then sent to Raspberry. In this controller, the SVM process was conducted. An algorithm using one versus others technique was used to identify and classify the gas. The process of the classification can be divided into two groups, i.e. Training and Testing as shown in Figure 2.

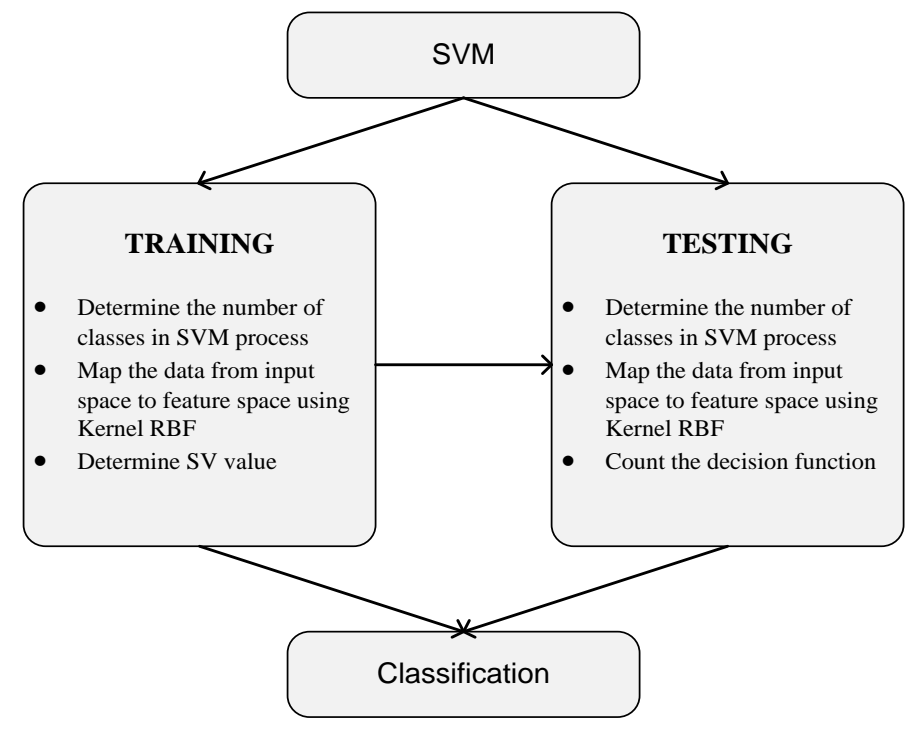

Figure 2. Classification Process

Three equations were used in training and testing process: i) Kernel Radial Basis Function (RBF) as shown in equation (4) was used to map the data from input space to feature space in the training and testing process of this research;

$$
K(\vec{x}, \vec{y})=\exp \left(-\gamma \gamma\|\vec{x}-\vec{y}\|^{2}\right)
$$

ii) quadrating programming in equation (5) was used to determine the support vector value $\alpha \neq 0$ that was obtained by counting the value of $\alpha_{1}, \alpha_{2}, \ldots \alpha_{n}$. 


$$
Q(\alpha)=\sum_{i=1}^{N} \alpha_{k}-\frac{1}{2} \sum_{i=1}^{N} \sum_{j=1}^{N} \alpha_{i} \alpha_{j} y_{i} y_{j} K\left\langle x_{i}, x_{j}\right\rangle
$$

The correlation data $x_{i}$ that correlates to $\alpha \neq 0$ as support vector can be achieved by using this programming; iii) equation (6) was used to count the decison function.

$$
f(x)=\operatorname{sign}\left(\sum_{i \in S V} \alpha_{i} y_{i} K\left(x_{i}, x\right)+\alpha_{i} y_{i} \lambda^{2}\right)
$$

\section{RESULTS AND DISCUSSION}

\subsection{Sensor Performances}

The sensors' performances that were measured were focused on the sensors' time response, sensors' peak response duration, the sensitivity and the stability response of the sensor. The speed of the sensor's response measured in different position was shown in Figure 3. Figure 3(a) and (b) shows that the gas sensor's response time to ethanol and methanol are almost the same. For $40 \mathrm{~cm}$ until $240 \mathrm{~cm}$ distance, they needed only about $20 \mathrm{~s}$ to respond the gas source. For ethanol response, there was a change at $320-720 \mathrm{~cm}$ where it needed longer respond time than methanol, around 50-60 s; while for methanol only needed 40-50 s. This condition continued until the longest distance above $800 \mathrm{~cm}$, where the response time to ethanol became slower than methanol. For Figure 3(c), the response time of acetone was faster than ethanol and methanol. These response time differences were due to some factors, such as temperature, humidity, and also the type of the odors themselves.

In the research, the temperature and the humidity were made as ideal as possible. Therefore, the cause of the differences was due to the type of the odor substances only. Acetone has heavier molecular weight than ethanol and methanol, thus it could reach the gas sensor more quickly than two other substances. The molecular weights are $46.06844 \mathrm{~g} / \mathrm{mol}$ for ethanol, $32.04 \mathrm{~g} / \mathrm{mol}$ for methanol, and $58.08 \mathrm{~g} / \mathrm{mol} \mathrm{for}$ acetone. They can evaporate quickly due to their low boiling point $\left(78^{\circ} \mathrm{C}, 64^{\circ} \mathrm{C}, 56^{\circ} \mathrm{C}\right.$ respectively). The heavy molecular weight of acetone made it not be easily to be diffused by the wind or tore apart by turbulent. Thus, the substances could move straight to the gas sensors with high concentration and can be detected more quickly than two other substances.

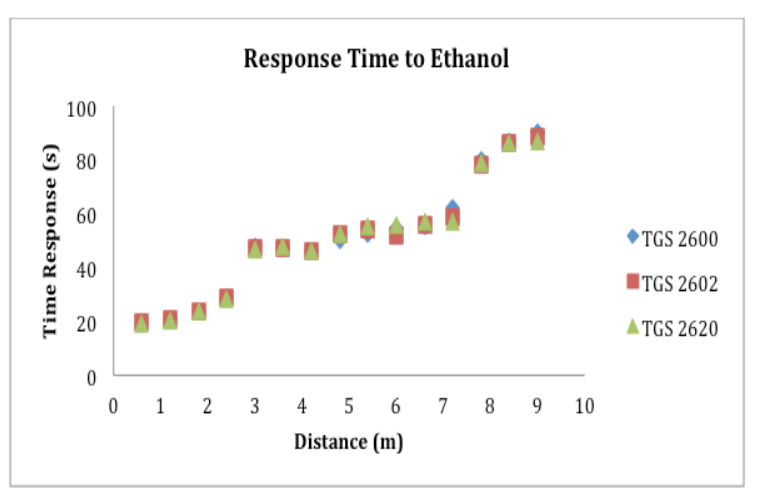

(a)

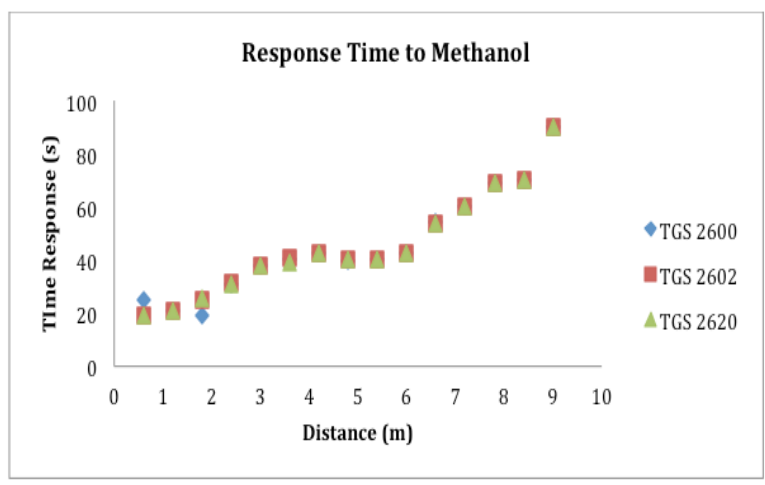

(b)

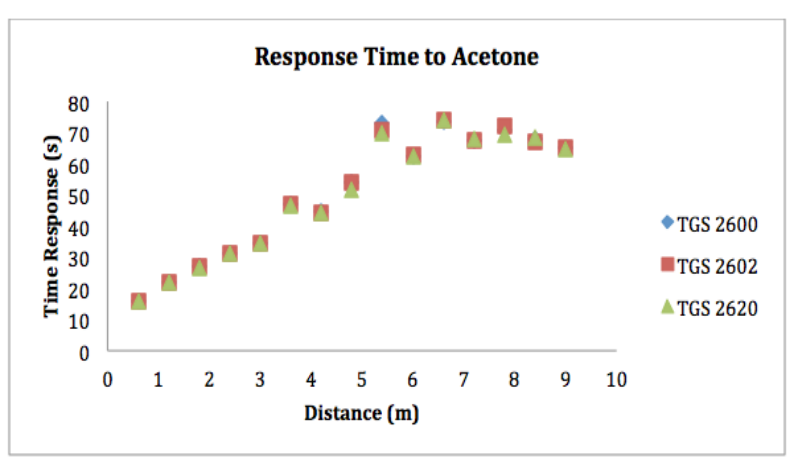

(c)

Figure 3. Sensor's time responses to some sources 
The sensors' peak response duration was represented in Figure 4. The peak response duration to the three sources, ethanol, methanol, and acetone showed different trends. However, all sources have almost the same characteristics. The nearest the sources to the gas sensors, the longest the response duration of the gas sensor be. The peak response duration of gas sensor to the ethanol and methanol at $40-400 \mathrm{~cm}$ decreased from $35 \mathrm{~s}$ into $10 \mathrm{~s}$.

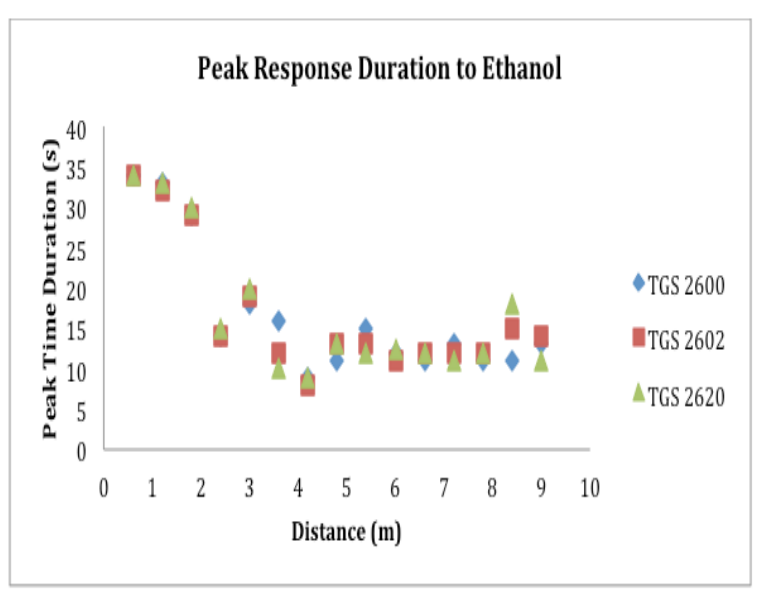

(a)

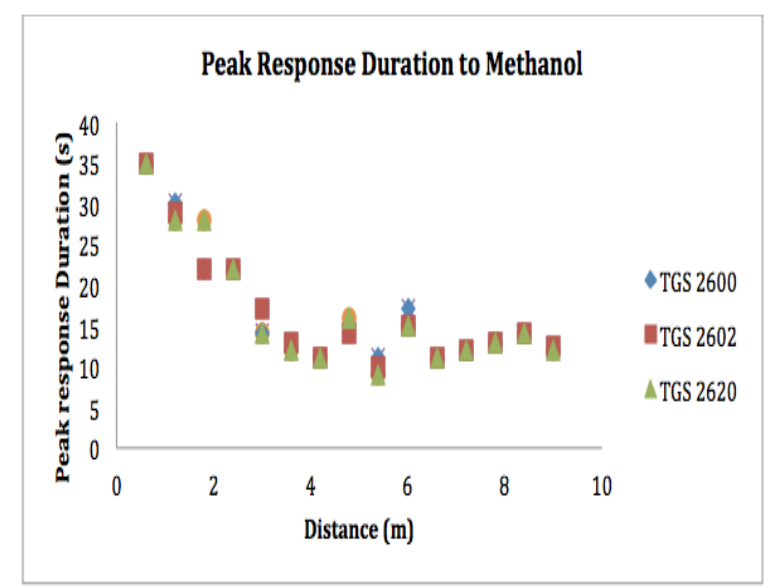

(b)

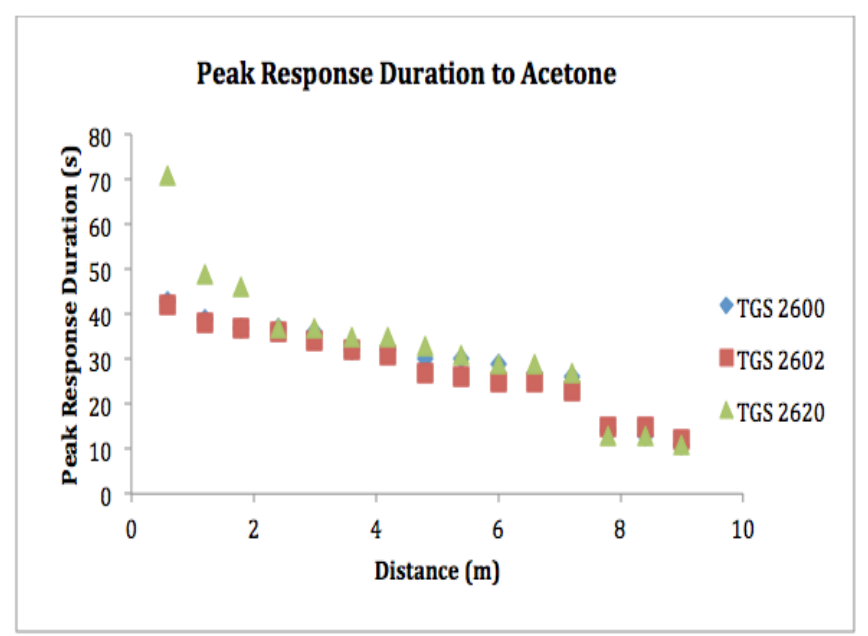

(c)

Figure 4. Sensor's peak duration responses for 3 different sources

The response seemed to be constant to the value of 10 second for the distance above of $400 \mathrm{~cm}$. While for the acetone, the duration time was higher than ethanol and methanol; it has value of around $30-40 \mathrm{~s}$ for the distance of 40-400 cm. It only experienced small changes until the distance of $760 \mathrm{~cm}$. This phenomenon was again caused by the molecular weight of those three odor sources. The heavier molecular weight of the acetone made the acetone could stay longer around the gas sensor. The lighter weight of ethanol and methanol made them to be easily to be dispersed by the wind.

The sensitivity and stability response of the sensors was displayed in Figure 5 and Figure 6 . Each of the sensors in response time testing showed that the response of them become slower due to the longer of the distance of the sources to reach the sensors. It was quite the same with the sensors' peak response duration where the response would be shorter when the distance between the source and the gas sensors become longer. The sensitivity of the sensors is shown in Figure 5. It indicated that the TGS sensor was sensitive enough to the change of the environment. The odor sources were exposed and unexposed to the robots interchangeably for obtaining the data. The source was switched on for $120 \mathrm{~s}$ and was switched off $120 \mathrm{~s}$. The data was achieved in the static position where the robots were placed in the straight face to face position. The concentration of the acetone that the robots measured was the highest one (above 900 of ADC value), 
while the methanol was the smallest one (above 500 of ADC value). The detecting values of each gas sensors were not directly change when the processes of on and off happened. All of the sensors waited around 30-50 seconds until they changed their reading value based on the condition of the gas sources.

It was due to the sensors needed more time to be back to its initial condition. The sensors still sensed the gas that was left in their surrounding (although the source has been switched off); hence, the sensors still read the gas concentration as high value for about 30-50 seconds after the gas source off. To overcome and minimize this transition condition, a fan was used. It could help to clean the gas residue that stacked to the sensors' area.

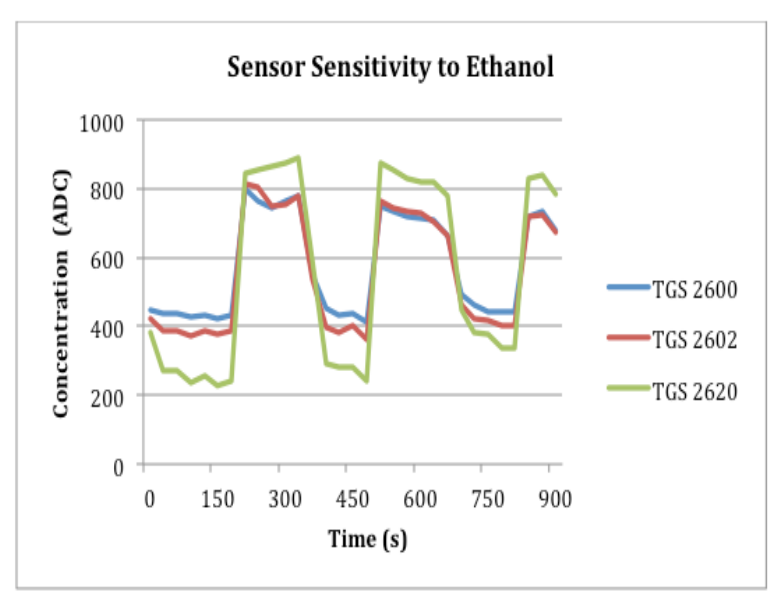

(a)

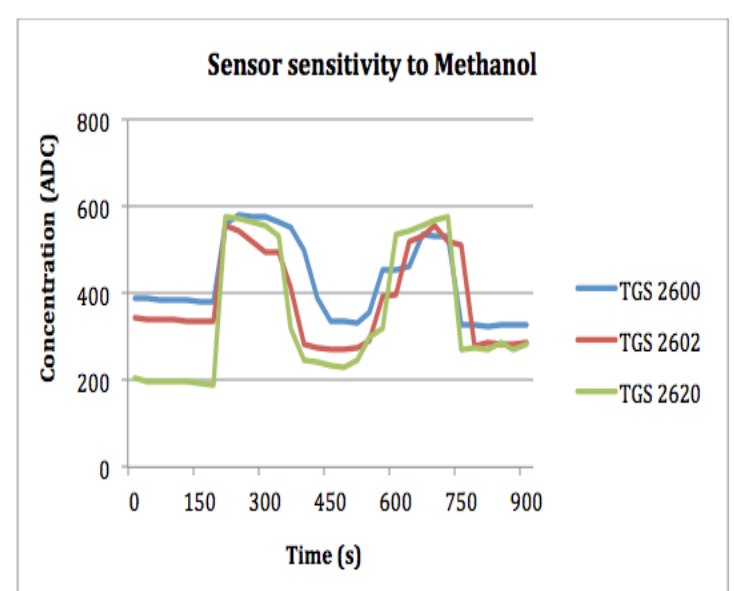

(b)

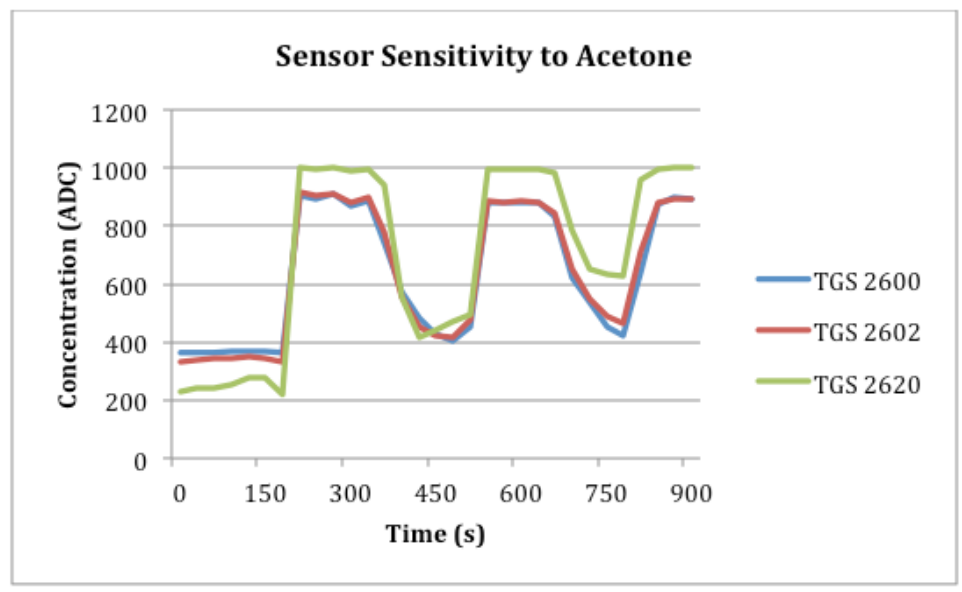

(c)

Figure 5. Sensor's sensitivity for 3 different sources

The stability response of the sensors was represented in Figure 6. This stability was needed in order to measure the time occupied by the sensors in detecting the source in a stable condition. By knowing the stability response, the mobile robots intelligences where the gas sensors were placed can be designed properly. In this research, the stability data got by collecting the sensors' response to the change of situation. The ability of the sensor to reach its initial condition was measured and recorded. From Figure 6, it can be stated that the gas sensors used in this experiments were stable enough. The concentration measured by the sensors was almost the same from the first sampling until the fifteenth sampling. Figure 6(a)-6(c) shows the stability of the sensors to the ethanol, methanol, and acetone. Figure 6(d) represents the sensors' stability of the sensors to all of the sources used in the experiment. The gas sensors used in this experiment has the stability response to each sources around 34 second until 45 second for each sensors. 


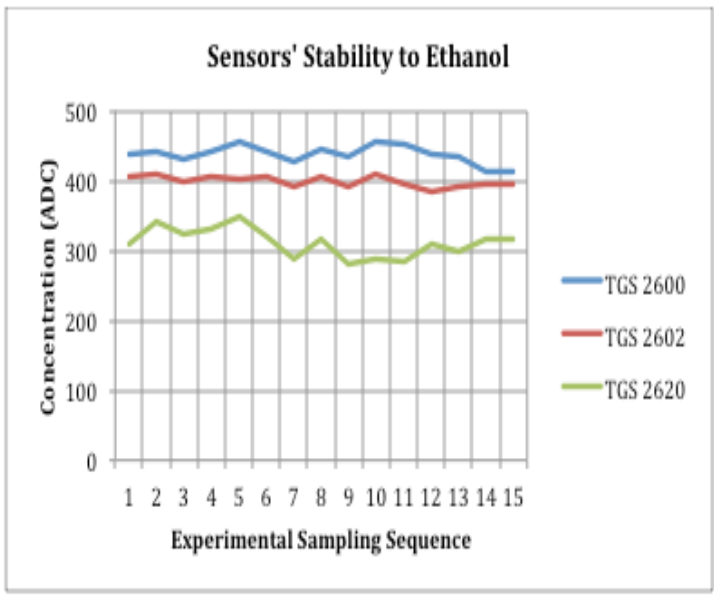

(a)

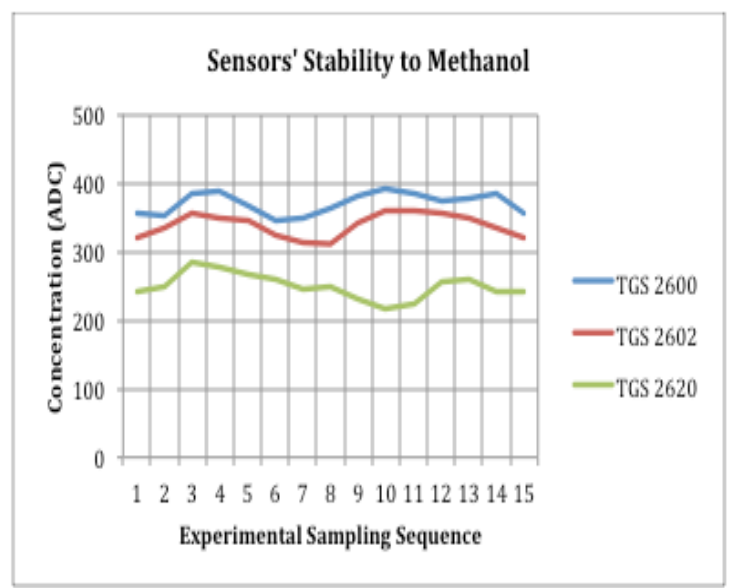

(b)

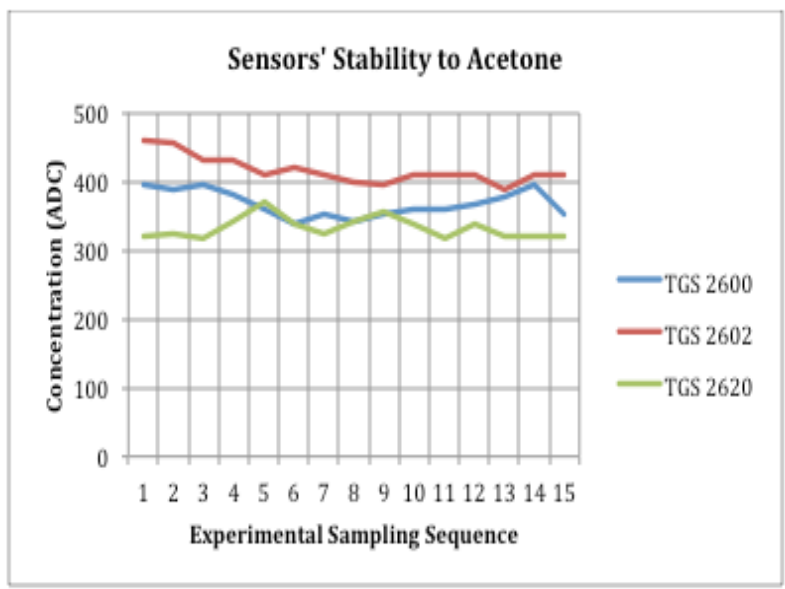

(c)

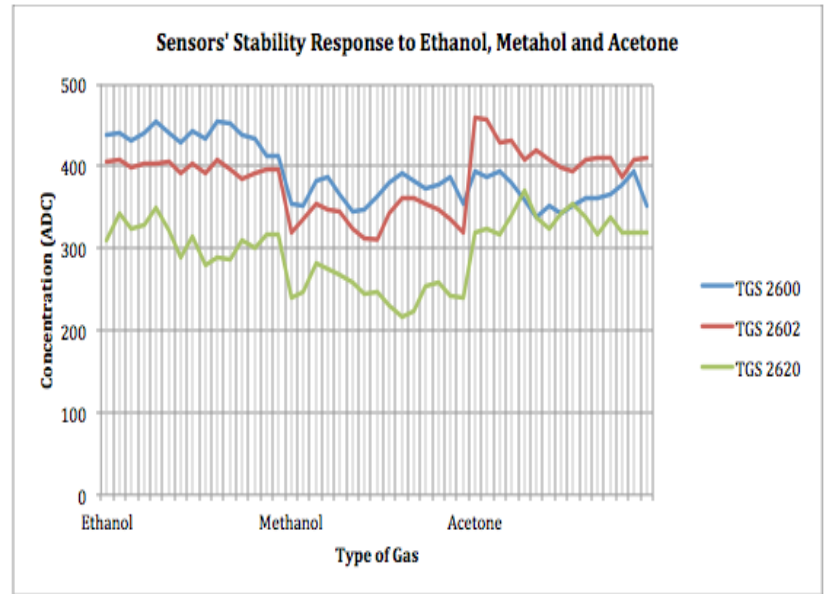

(d)

Figure 6. Sensor's stability for 3 different sources

\subsection{Collecting Datasets}

The training datasets were got from the gas sensors of the robots that were placed in a fix place approximate $60 \mathrm{~cm}$ from the source. The choice of the $60 \mathrm{~cm}$ away from the source as the training datasets was based on the characteristic of the sensor response time, sensor peak response duration, stability and sensitivity. At this position, gas sensors showed their good performance. 
The experimental environment was then exposed to the gas source for 20 seconds. Then, the data came from the 3 sensors of each robot were plotted in one graphics as shown in Figure 7. These data became the training datasets for the classification. The data was grouped into their classes. When exposed to the ethanol source, the data that was sensed by TGS 2600, TGS 2602, and TGS 2620 as ethanol classes were recorded, as well as the data of the other source, i.e. methanol and acetone. Figure 7(b) and 7(c) shows the response of the gas sensors for methanol class and the acetone class respectively.

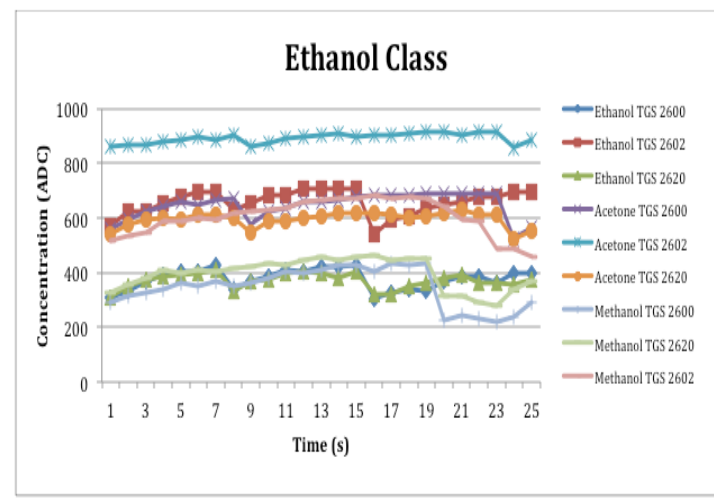

(a)

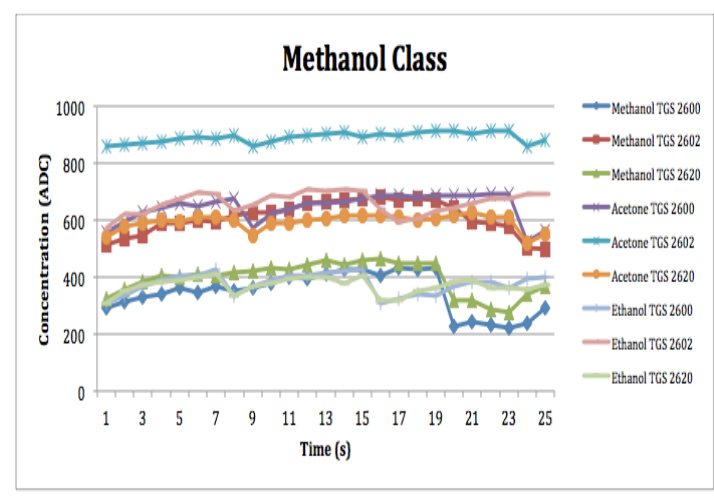

(b)

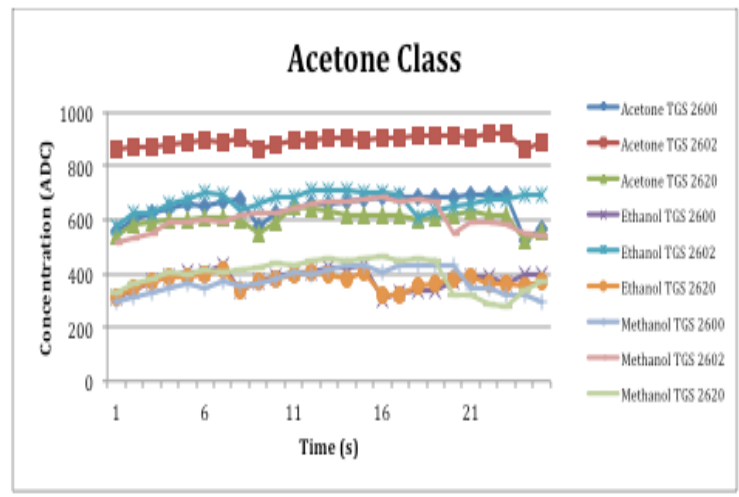

(c)

Figure 7. Classes used as data training for gas classification

\subsection{Odor Classification using Support Vector Machine}

In this research, two modes of experimental set up will be used in detecting the odor source, namely: static and mobile sensors. Static sensor is a system that only does the detection process without changing the position, while mobile sensor has the opposite characteristics, i.e. by changing the sensors position to the odor sources. Based on the detection result, the robots should be able to classify the odor type. The process of the classification using SVM approach was established in raspberry while the navigation of the mobile robots was processed in Arduiono.

\subsubsection{Static sensor}

Static sensors data were obtaining by deploying the robots that were equipped with gas sensors TGS 2600, TGS 2602, and TGS 2620 to the experimental environment. The robots were placed in front of the gas source and moved them to a certain place manually to get further from the source (in scale of $0.5 \mathrm{~m}$ ) in each movement. 4 positions $(0.5,1.0,1.5$, and $2.0 \mathrm{~m})$ were tested to see the superiority of the robots in determining the odor source. The odor classification testing was conducted 10 times for each source. The data was recorded in Table 1 . Most of them were successful in specifying the source. For the range of 0.5 until $2.0 \mathrm{~m}$, all the robots could determine the ethanol and acetone correctly with the success rate $90 \%$. From 10 times testing, all of the robots could determine the source correctly for 9 times. There was one time where the robot got $100 \%$ success. G1-2 in the $0.5 \mathrm{~m}$ distance could specify methanol source correctly for 10 times. 
Table 1. Confusion Matrix of gas classification in dynamic experiment

\begin{tabular}{|c|c|c|c|c|c|c|c|c|c|c|c|}
\hline \multirow{11}{*}{ 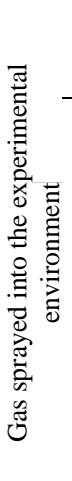 } & \multicolumn{11}{|c|}{ Gas Classified by the Robots } \\
\hline & $\begin{array}{c}\text { Distance } \\
(\mathrm{m})\end{array}$ & Gas Type & \multicolumn{3}{|c|}{ Ethanol } & \multicolumn{3}{|c|}{ Methanol } & \multicolumn{3}{|c|}{ Acetone } \\
\hline & & Ethanol & 9 & 9 & 9 & 1 & 0 & 0 & 0 & 1 & 1 \\
\hline & & Acetone & 1 & 0 & 1 & 0 & 1 & 0 & 9 & 9 & 9 \\
\hline & & Ethanol & 9 & 9 & 9 & 1 & 0 & 1 & 0 & 1 & 0 \\
\hline & 1 & Methanol & 1 & 0 & 0 & 9 & 9 & 9 & 0 & 1 & 1 \\
\hline & 1.5 & Methanol & 1 & 1 & 0 & 9 & 9 & 9 & 0 & 0 & 1 \\
\hline & & Acetone & 0 & 0 & 0 & 1 & 1 & 1 & 9 & 9 & 9 \\
\hline & & Ethanol & 9 & 9 & 9 & 0 & 0 & 0 & 1 & 1 & 1 \\
\hline & 2 & Methanol & 0 & 1 & 1 & 9 & 9 & 9 & 1 & 0 & \\
\hline & & Acetone & 1 & 0 & 1 & 0 & 1 & 0 & 9 & 9 & 9 \\
\hline
\end{tabular}

The accuracy, precision, and recall for each class can be calculated based on the data obtained in Table 1. The result of the calculation is presented in Table 2. The stability of the robots was around $89.5-90.8 \%$, the accuracy was $89.2-90.8 \%$, and recall around 89.2-90.8\%. It indicated that the gas sensors in static experiment have good performance. The distance of the robots from the source did not affect the ability of the robot to determine the type of odor they sensed. With different distance, most of them had stability, accuracy, and recall above $89.0 \%$. The SVM approach based on the MOS sensors' performance in static modes showed a great success in determining the odor type.

Table 2. Calculation of Precision, Accuracy and Recall in Dynamic Experiment

\begin{tabular}{|c|c|c|c|c|c|c|c|c|c|c|}
\hline \multirow{2}{*}{$\begin{array}{l}\text { Distance } \\
(\mathrm{m})\end{array}$} & \multirow{2}{*}{ Gas Type } & \multicolumn{3}{|c|}{ G1-1 } & \multicolumn{3}{|c|}{ G1-2 } & \multicolumn{3}{|c|}{ G1-3 } \\
\hline & & Pre & Acc & $\operatorname{Rec}$ & Pre & Acc & $\operatorname{Rec}$ & Pre & Acc & $\operatorname{Rec}$ \\
\hline \multirow{3}{*}{0.5} & Ethanol & 81.8 & \multirow{2}{*}{86.7} & 90.0 & 100.0 & \multirow{3}{*}{93.3} & 90.0 & 81.8 & \multirow{3}{*}{90.0} & 90.0 \\
\hline & Methanol & 88.9 & & 80.0 & 90.9 & & 100.0 & 100.0 & & 90.0 \\
\hline & Acetone & 90.0 & \multirow{4}{*}{90.0} & 90.0 & 90.0 & & 90.0 & 90.0 & & 90.0 \\
\hline \multirow{4}{*}{1} & Ethanol & 81.8 & & 90.0 & 90.0 & & 90.0 & 100.0 & \multirow{3}{*}{90.0} & 90.0 \\
\hline & Methanol & 90.0 & & 90.0 & 100.0 & 90.0 & 90.0 & 81.8 & & 90.0 \\
\hline & Acetone & 100.0 & & 90.0 & 81.8 & & 90.0 & 90.0 & & 90.0 \\
\hline & Ethanol & 90.0 & \multirow{3}{*}{90.0} & 90.0 & 90.0 & & 90.0 & 100.0 & \multirow{3}{*}{90.0} & 90.0 \\
\hline \multirow[t]{3}{*}{1.5} & Methanol & 90.0 & & 90.0 & 81.8 & 90.0 & 90.0 & 81.8 & & 90.0 \\
\hline & Acetone & 90.0 & & 90.0 & 100.0 & & 90.0 & 90.0 & & 90.0 \\
\hline & Ethanol & 90.0 & \multirow{3}{*}{90.0} & 90.0 & 90.0 & & 90.0 & 81.8 & & 90.0 \\
\hline \multirow[t]{2}{*}{2} & Methanol & 100.0 & & 90.0 & 90.0 & 90.0 & 90.0 & 100.0 & 90.0 & 90.0 \\
\hline & Acetone & 81.8 & & 90.0 & 90.0 & & 90.0 & 90.0 & & 90.0 \\
\hline \multicolumn{2}{|c|}{ Average } & 89.5 & 89.2 & 89.2 & 91.2 & 90.8 & 90.8 & 90.6 & 90.0 & 90.0 \\
\hline
\end{tabular}

\subsubsection{Mobile sensors}

For the dynamic sensors, the experimental data was got obtaining by placing the robots near the sources with two starting points, $1 \mathrm{~m}$ and $2 \mathrm{~m}$. They were commanded to get closer to the sources using their intelligences and asked to decide what kind of sources they have detected. Each sources was dispersed to the environment alternately. The robots should able to recognize the odor using their intelligences that have been embedded to them. The robots were introduced to the sources (ethanol, methanol, and acetone) 10 times in each distance. Figure 7 was the examples of the data sent by the robots to the server. The first number of each picture in the series data represented in each pictures indicates the type of robots. 1 indicates G1-1 robot, 2 means G1-2 robot, and 3 for G1-3 robot. The last parameters in each line of data series show the type of data sensed.

Figure 7a shows that at the first, G1-1 robot classified the odor its sensed as methanol, then after several times it decided that it was ethanol. All of the robots at last decided that the odor they sensed as ethanol. When the data sent to the server be the same with the odor source for several times, then, in this condition, it can be concluded that the robots have been able to recognize and classify the odor correctly. Figure 7(b) until Figure 7(f) show part of the data sent by the robot to the server, Figure 7(a) until 7(c) for 1 $\mathrm{m}$ distance starting point and Figure 7(d)-Figure 7(f) for $2 \mathrm{~m}$ distance starting point. Table 3 show the confusion matrix for the classification in dynamic experimental setup while the calculation of the precision, accuracy and recall is shown in Table 4. The dynamic experiment also show the succes in classifying the odor sources. The average of precision success was $93.8-97.0 \%$, the accuracy was $93.3-96.7 \%$, and the recall was $93.3-96.7 \%$. This values indicates that the sensors were selective to the odor they sensed. 


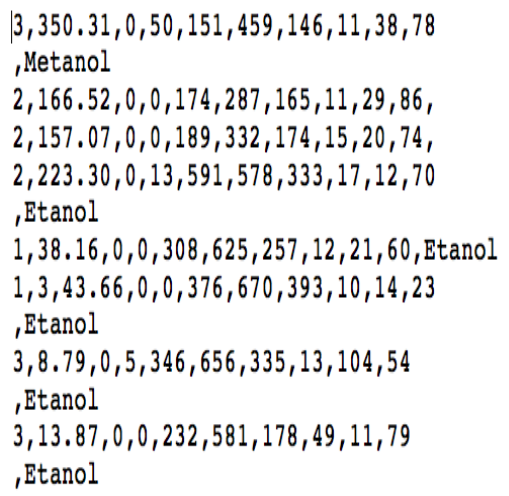

(a) Ethanol

$2,201.23,0,162,73,89,59,84,149,91$, Metanol

$3,100.86,0,0,75,520,192,20,13,62$

,Metanol

$2,240.03,0,162,77,93,64,149,164,37$, Metanol

$3,88.42,0,0,633,822,635,12,16,50$

, Etanol

$2,224.10,0,204,74,83,56,151,161,23$

, Etanol

$2,275.22,0,259,709,822,619,67,17,83$

,Etanol

$1,88.29,0,35,575,710,504,36,5,50$

,Etanol

$1,73.39,0,35,551,698,583,62,35,51$

, Aseton

$1,88.29,0,35,575,710,504,36,5,50$

,Etanol
$2,217.70,0,0,502,690,445,119,16,96$ ,Metanol

$2,197.86,0,0,494,694,445,123,13,31$ ,Metanol

$3,68.86,0,41,598,821,654,57,20,18$ ,Metanol

$1,78.71,0,14,266,231,310,62,127,31$ ,Metanol

$1,81.48,0,15,278,250,309,63,131,29$ ,Metanol
$1,93.25,0,0,661,868,506,42,12,28$ , Aseton

$1,44.63,0,0,94,708,53,73,18,100$ , Aseton

$3,59.25,0,0,562,857,551,30,30,44$ , Aseton

$3,6.69,0,0,560,870,474,59,86,49$

, Aseton

$2,154.91,0,12,80,459,91,72,20,81$, Metanol $2,147.58,0,14,74,460,96,73,21,91$ ,Aseton (b) Methanol

$2,217.70,0,0,502,690,445,119,16,96$, Etanol $2,197.86,0,0,494,694,445,123,13,31$, Etanol $2,214.38,0,0,492,697,440,26,13,32$ ,Metanol

$3,68.86,0,41,598,821,654,57,20,18$ ,Aseton

$3,13.94,0,44,556,807,592,42,14,14$ , Aseton

$3,78.60,0,7,555,831,695,59,18,14$ , Metanol

$1,78.71,0,14,266,231,310,62,127,31$ $1,81.48,0,15,278,250,309,63,131,29$ $1,78.89,0,19,306,277,336,65,124,29$ ,Metanol (c) Acetone

$1,29.39,0,54,84,366,97,65,58,39$ $1,42.13,0,105,74,325,100,64,12,39$ $1,356.90,0,2,825,909,734,11,25,96$ Aseton

$1,82.89,0,2,801,900,586,6,9,87$ Aseton

$3,59.49,0,0,2,0,0,50,15,57$

$3,57 \cdot 16,0,0,4,2,0,42,15,59$

$3,50.29,0,0,2,0,4,49,13,60$

$3,98.22,0,12,2,0,4,29,10,109$

$3,88.73,0,12,2,0,0,49,10,110$

$3,30.31,0,0,198,756,204,29,12,75$, Etanol

$3,82.40,0,3,630,745,477,28,15,66$

Aseton

$2,159,46,0,0,88,558,161,19,15,22$, Metanol $2,173.86,0,0,92,569,162,6,17,25$, Metanol

$2,154.91,0,12,80,459,91,72,20,81$ Aseton

(d) Ethanol

(e) Methanol

(f) Acetone

Figure 7. Classification result, (a) to (c) at $1 \mathrm{~m}$ distance, (d) to (f) at $2 \mathrm{~m}$ distance

Table 3. ConfusionMatrix of gas classificationin dynamic experiment

\begin{tabular}{|c|c|c|c|c|c|c|c|c|c|c|c|}
\hline \multirow{6}{*}{ 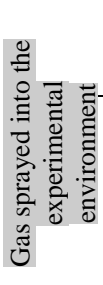 } & \multicolumn{11}{|c|}{ Gas Classified by the Robots Rate } \\
\hline & $\begin{array}{c}\text { Starting } \\
\text { point }(\mathrm{m})\end{array}$ & Gas Type & \multicolumn{3}{|c|}{ Ethanol } & \multicolumn{3}{|c|}{ Methanol } & \multicolumn{3}{|c|}{ Acetone } \\
\hline & & Ethanol & 10 & 10 & 10 & 0 & 0 & 0 & 0 & 0 & 0 \\
\hline & & Acetone & 0 & 0 & 0 & 0 & 0 & 0 & 10 & 10 & 10 \\
\hline & & Ethanol & 10 & 9 & 10 & 0 & 0 & 0 & 0 & 1 & 0 \\
\hline & 2 & Methanol & 1 & 1 & 1 & 8 & 9 & 9 & 1 & 0 & 0 \\
\hline
\end{tabular}

Table 4. Calculation of precision, accuracy and recall in dynamic experiment

\begin{tabular}{ccccccccccc}
\hline $\begin{array}{c}\text { Starting } \\
\text { point }(\mathrm{m})\end{array}$ & Gas Type & \multicolumn{3}{c}{ G1-1 } & \multicolumn{3}{c}{ G1-2 } & \multicolumn{3}{c}{ G1-3 } \\
& & Pre & Acc & Rec & Pre & Acc & Rec & Pre & Acc & Rec \\
\hline \multirow{2}{*}{1} & Ethanol & 100.0 & 96.7 & 100.0 & 90.9 & 96.7 & 100.0 & 100.0 & 100.0 & 100.0 \\
& Methanol & 100.0 & 96.7 & 90.0 & 100.0 & 96.7 & 90.0 & 100.0 & 100.0 & 100.0 \\
& Acetone & 90.9 & 96.7 & 100.0 & 100.0 & 96.7 & 100.0 & 100.0 & 100.0 & 100.0 \\
2 & Ethanol & 90.9 & 93.3 & 100.0 & 81.8 & 90.0 & 90.0 & 83.3 & 93.3 & 100.0 \\
& Methanol & 100.0 & 93.3 & 80.0 & 100.0 & 90.0 & 90.0 & 100.0 & 93.3 & 90.0 \\
& Acetone & 90.9 & 93.3 & 100.0 & 90.0 & 90.0 & 90.0 & 100.0 & 93.3 & 90.0 \\
& Average & 95.5 & 95.0 & 95.0 & 93.8 & 93.3 & 93.3 & 97.2 & 96.7 & 96.7 \\
\hline
\end{tabular}

\section{CONCLUSION}

From the research, it can be concluded that the performance of the MOS sensors could help in finding a good datasets. The robots could recognize the type of odor they sensed successfully. However, the 
coverage area of the sensed odor was only about $2 \mathrm{~m}$. When they were applied to further distance, they would made a wrong classification for odor they sensed. Therefore, it needs a more comphrehensive investigation in developing this approach. For future reseach, we would like to implement more intelligences in order to overcome this limitation.

Metal Oxide Semiconductors sensors are good to be implemented in odor classification. They are stable, sensitive to the changes, and really selective. However, some treatments should be done before employing these sensors in odor classification. These sensor would not show their stability when they are not being heated for several hours of their usage. They would measure wrong concentration and the value of measurement would swing with a wide range. Heating before usage become one of the key in odor classification task. The other problems often occured are unlinear data. Sometimes, the data of the sensors has a wide range of variation. If it happened, a preprocessing data is needed. The prepocessing data could help to ommit the error data occur in the experiment.

\section{ACKNOWLEDGEMENTS}

Authors thank to the Indonesian Ministry of Research, Technology and National Education (RISTEKDIKTI) and State Polytechnic of Sriwijaya under Research Collaboration for their financial supports in Competitive Grants Project. This paper is also one of our Ph.D. projects. Our earnest gratitude also goes to Mr. Marco Trincavelli and Mr. Victor Hernandez Bennet who have given valuable information about how to set up a good odor experiment and how to get a good datasets for odor classification. We also would like to say thank to all researchers in Signal Processing and Control Laboratory, Electrical Engineering, State Polytechnic of Sriwijaya who provided companionship and sharing of their knowledge.

\section{REFERENCES}

[1] J. Lobo, et al., "Sensors for Mobile Robot Navigation."

[2] L. Seminara, et al., "Piezoelectric polymer transducer arrays for flexible tactile sensors," IEEE Sens. J., vol/issue: 13(10), pp. 4022-4029, 2013.

[3] S. E. Zohora and N. Hundewale, "Chemical Sensors Employed In Electronic Noses: A Review," Soft Comput. Eng., vol/issue: 3(2), pp. 405-408, 2013.

[4] L. Zhang, et al., "A novel sensor selection using pattern recognition in electronic nose," Measurement, vol. 54, pp. 31-39, 2014

[5] B. Ji, et al., "Design and performance evaluation of the upgraded portable monitoring unit for air quality in animal housing," vol. 124, pp. 132-140, 2016.

[6] N. L. Husni, et al., "New Challenges in Air Quality Sensing using Robotic Sensor Network," 2013.

[7] S. Nurmaini, "Low-cost robotic sensor networks platform for air quality monitoring," vol. 145.

[8] N. L. Husni, et al., "Odor Localization Sub Tasks : A Survey."

[9] D. Chengjun, et al., "Development on Gas Leak Detection and Location System Based on Wireless Sensor Networks," 2011 Third Int. Conf. Meas. Technol. Mechatronics Autom., vol/issue: 1(6), pp. 1067-1070, 2011.

[10] J. Banick, et al., "Monitoring Carbon Dioxide and Methane Levels above Retired Landfill and Forest Control Sites with a Tethered Aerostat to Determine Remediation Effectiveness Jesse Banick, Kathryn Lenz, Jonathan Sanders, Jeshanah Zolkowski 1 University of Wisconsin-Fox Val."

[11] A. D. Wilson, "Diverse applications of electronic-nose technologies in agriculture and forestry," Sensors (Switzerland), vol/issue: 13(2), pp. 2295-2348, 2013.

[12] V. B. Raj, et al., "Sensors and Actuators B : Chemical Oxide thin films ( $\mathrm{ZnO}, \mathrm{TeO} 2$, SnO 2 , and TiO 2 ) based surface acoustic wave ( SAW ) E-nose for the detection of chemical warfare agents," vol. 178, pp. 636-647, 2013.

[13] C. A. O. Pinatti, et al., "An electronic nose for the detection of Sarin, Soman and Tabun mimics and interfering agents," Sensors and Actuators B: Chemical, vol. 202, pp. 31-37, 2014.

[14] M. Turduev, et al., "Experimental studies on chemical concentration map building by a multi-robot system using bio-inspired algorithms," 2012.

[15] T. Lochmatter, "Bio-Inspired and Probabilistic Algorithms for Distributed Odor Source Localization using Mobile Robots," vol. 4628, 2010.

[16] M. L. R. Mendez, et al., "Evaluation of oxygen exposure levels and polyphenolic content of red wines using an electronic panel formed by an electronic nose and an electronic tongue," Food Chem., vol. 155, pp. 91-97, 2014.

[17] D. Melucci, et al., "Rapid direct analysis to discriminate geographic origin of extra virgin olive oils by flash gas chromatography electronic nose and chemometrics," Food Chem., vol. 204, pp. 263-273, 2016.

[18] M. Russo, et al., "Non-destructive flavour evaluation of red onion (Allium cepa L.) Ecotypes: An electronic-nosebased approach," Food Chem., vol/issue: 141(2), pp. 896-899, 2013.

[19] S. Zampolli, et al., "An electronic nose based on solid state sensor arrays for low-cost indoor air quality monitoring applications," Sensors Actuators, B Chem., vol/issue: 101(1-2), pp. 39-46, 2004.

[20] A. C. Romain and J. Nicolas, "Long term stability of metal oxide-based gas sensors for e-nose environmental applications: An overview," Sensors and Actuators, B: Chemical, vol/issue: 146(2), pp. 502-506, 2010.

[21] N. Barsan, et al., "Metal oxide-based gas sensor research : How to ?," vol. 121, pp. 18-35, 2007. 
[22] G. F. Fine, et al., "Metal oxide semi-conductor gas sensors in environmental monitoring," Sensors, vol/issue: 10(6), pp. 5469-5502, 2010.

[23] M. Trincavelli and A. Loutfi, "Feature selection for gas identification with a mobile robot," Proc. - IEEE Int. Conf. Robot. Autom., pp. 2852-2857, 2010.

[24] A. Marjovi and L. Marques, "Optimal spatial formation of swarm robotic gas sensors in odor plume finding," Auton. Robots, vol/issue: 35(2-3), pp. 93-109, 2013.

[25] J. Murlis, "Odor Plumes And How Insects Use Them," Annu. Rev. Entomol., vol/issue: 37(1), pp. 505-532, 1992.

[26] L. I. Ji-gong, et al., "Odor-source Searching using a Mobile Robot in Time-variant Airflow Environments with Obstacles,” pp. 8559-8564, 2014.

[27] J. G. Li, et al., "Speed limitation of a mobile robot and methodology of tracing odor plume in airflow environments," Procedia Eng., vol. 15, pp. 1041-1045, 2011.

[28] J. Zhou, et al., "A bionic plume tracing method with a mobile robot in outdoor time-varying airflow environment," 2015 IEEE Int. Conf. Inf. Autom., no. 61304153, pp. 2351-2355, 2015.

[29] S. Zhang, et al., "Swarm olfactory search in turbulence environment," Process. 2014 Int. Conf. Multisens. Fusion Inf. Integr. Intell. Syst. MFI 2014, vol. 2, 2014.

[30] D. Chang, et al., "A Bio-inspired Plume Tracking Algorithm for Mobile Sensing Swarms in Turbulent Flow."

[31] S. Güney and A. Atasoy, "Sensors and Actuators B: Chemical Multiclass classification of n -butanol concentrations with $\mathrm{k}$-nearest neighbor algorithm and support vector machine in an electronic nose," Sensors Actuators B. Chem., vol. 166-167, pp. 721-725, 2012.

[32] A. Marjovi and L. Marques, "Swarm robotic plume tracking for intermittent and time-variant odor dispersion," 2013 Eur. Conf. Mob. Robot. ECMR 2013 - Conf. Proc., pp. 379-384, 2013.

[33] S. Omatu, "Odor Classification by Neural Networks," no. c, pp. 154-159, 2013.

[34] A. Marjovi and L. Marques, "Optimal Swarm Formation for Odor Plume Finding," IEEE Trans. Cybern., 2014.

[35] N. Nimsuk and T. Nakamoto, "Improvement of capability for classifying odors in dynamically changing concentration using QCM sensor array and short-time Fourier transform,” vol. 127, pp. 491-496, 2007.

[36] Q. Ouyang, et al., "Molecular and Biomolecular Spectroscopy Intelligent sensing sensory quality of Chinese rice wine using near infrared spectroscopy and nonlinear tools," Spectrochim. Acta Part A Elsevier, vol. 154, pp. 4246, 2016.

[37] B. Fang, et al., "AirSense: An Intelligent Home-based Sensing System for Indoor Air Quality Analytics," UBICOMP' '16, pp. 109-119, 2016.

[38] S. T. Sarkar, et al., "Towards biological plausibility of electronic noses: A spiking neural network based approach for tea odour classification," Neural Networks, vol. 71, pp. 142-149, 2015.

[39] S. Singh, et al., "Fuzzy neural computing of coffee and tainted-water data from an electronic nose," Sensors Actuators B Chem., vol/issue: 30(3), pp. 185-190, 1996.

[40] T. Roppel and D. M. Wilson, "Biologically-inspired pattern recognition for odor detection," Pattern Recognit. Lett., vol/issue: 21(3), pp. 213-219, 2000.

[41] D. Schild, "Principles Of Odor Coding And A Neural Network For Odor Discrimination," Biophys. J., vol. 54, pp. 54-56, 1988.

[42] P. Jiang, et al., "A Novel Object Recognition Method for Mobile Robot Localizing a Single Odor / Gas Source in Complex Environments," pp. 2-6, 2008.

[43] M. Trincavelli, et al., "Classification of Odours with Mobile Robots Based on Transient Response," pp. 22-26, 2008.

[44] M. Trincavelli, et al., "Odour classification system for continuous monitoring applications," Sensors Actuators, B Chem., vol/issue: 139(2), pp. 265-273, 2009.

[45] M. Trincavelli, et al., "Classi cation of Odours for Mobile Robots Using an Ensemble of Linear Classi ers," pp. 14.

[46] W. Lu, et al., “Air Pollutant Parameter Forecasting Using Support Vector Machines,” pp. 0-5, 2002.

[47] M. Yu, "Expert Systems with Applications Multi-criteria ABC analysis using artificial-intelligence-based classification techniques," Expert Syst. Appl., 2010.

[48] A. Bermak, et al., "Pattern Recognition Techniques for Odor Discrimination in Gas Sensor Array," vol. X, 2006.

[49] A. Loutfi, et al., "Gas Distribution Mapping of Multiple Odour Sources using a Mobile Robot," pp. 1-15.

[50] R. Gutierrez-osuna and H. T. Nagle, "A Method for Evaluating Data-Preprocessing Techniques for Odor Classification with an Array of Gas Sensors," vol/issue: 29(5), pp. 626-632, 1999.

[51] A. Einollahi, "Selectivity Enhancement for a Temperature Modulated Electronic Nose using Phase Space and Dynamic Moments," 2012.

[52] V. E. Bochenkov and G. B. Sergeev, "Sensitivity, Selectivity, and Stability of Gas-Sensitive Metal-Oxide Nanostructures," vol. 3, pp. 31-52, 2010.

[53] X. Zhou, et al., "Highly sensitive acetone gas sensor based on porous ZnFe 2 O 4 nanospheres," Sensors Actuators B. Chem., vol. 206, pp. 577-583, 2015.

[54] T. Maekawa, et al., "Odor identification using a SnO 2 -based sensor array," vol. 80, pp. 3-6, 2001.

[55] Z. Wen, et al., "Rhombus-shaped Co3 O4 nanorod arrays for high-performance gas sensor," Sensors Actuators B. Chem., vol. 186, pp. 172-179, 2013.

[56] Q. Jia, et al., "Rapid and selective detection of acetone using hierarchical $\mathrm{ZnO}$ gas sensor for hazardous odor markers application," J. Hazard. Mater., vol. 276, pp. 262-270, 2014.

[57] N. L. Husni, et al., "Odor Localization Sub Tasks : A Survey," J. Telecommun. Electron. Comput. Eng., vol/issue: 
$8(3), 2016$.

[58] W. Khalaf, et al., "Least Square Regression Method for Estimating Gas Concentration in an Electronic Nose System," pp. 1678-1691, 2009.

[59] L. Gugel, et al., "Machine Olfaction Using Time Scattering of Sensor," pp. 1-19, 2016.

[60] H. J. Kwon, et al., "Multiple odor recognition and source direction estimation with an electronic nose system," Int. J. Distrib. Sens. Networks, vol. 2013, 2013.

\section{BIOGRAPHIES OF AUTHORS}
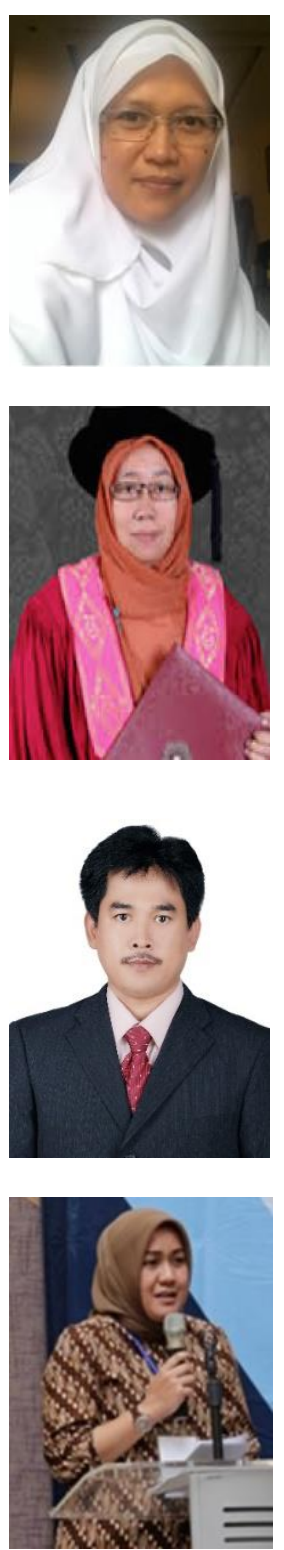

Nyayu Latifah Husni was born on 3rd of May, 1976. She finished her bachelor degree at Sriwijaya University of Electrical Engineering on July 17th,1999. After finished her bachelor, she became an assistance of High Voltage Engineering lecturer at Sriwijaya University. In 2001, She was accepted as junior lecturer at State Polytechnic of Sriwijaya. Then, she continued her master degree at Indonesia University of Electrical Device department in 2004. She got her master tittle in 2007. She is active in teaching and having researches, especially in the area of robotics of control engineering and artificial intelligent. She got various of financial supports for her research in air quality monitoring and odor localization using swarm robots area. Now, She is having her doctoral degree at Sriwijaya University of Engineering department.

Siti Nurmaini is now being active in intelligent system research at computer science department, Universitas Sriwijaya. Her research areas are machine learning, deep learning, robotic and control, and also bioinformatics.

Irsyadi Yani was born on December $25^{\text {th }}$, 1971. He received the B.E. degree in Mechanical Engineering from the University of Sriwijaya, Indonesia, in 1996, and the M.Eng. Degrees in Mechanical Engineering from Toyohashi University of Technology, Japan, and Phd from National University of Malaysia. He joined the Department of Mechanical Engineering, Universitiy of Sriwijaya, as a Lecturer. His current research interests include Artificial Intelligence, Automatic Sorting System, and Finite Element Analysis.

Ade Silvia Handayani was born on 30th of September, 1976. She finished her bachelor degree at Sriwijaya University of Electrical Engineering on July 17th,1999. She was accepted as junior lecturer at State Polytechnic of Sriwijaya in 2000. Then, she continued her master degree at Institut Teknologi Bandung (ITB) in 2001. She got her master tittle in 2004. Her current research interests are telecommunication and artificial intelligent. Now, She is having her doctoral degree at Sriwijaya University of Engineering department. 